\title{
Monolinguisme, plurilinguisme et translinguisme chez Paul Celan
}

À propos de la genèse du poème « Huhediblu »

\section{Dirk Weissmann}

\section{(2) OpenEdition}

\section{Journals}

Édition électronique

URL : http://journals.openedition.org/genesis/2606

DOI : 10.4000/genesis.2606

ISSN : 2268-1590

Éditeur :

Presses universitaires de Paris Sorbonne (PUPS), Société internationale de génétique artistique littéraire et scientifique (SIGALES)

\section{Édition imprimée}

Date de publication : 4 juin 2018

Pagination : 35-50

ISBN : 979-10-231-0604-6

ISSN : $1167-5101$

\section{Référence électronique}

Dirk Weissmann, « Monolinguisme, plurilinguisme et translinguisme chez Paul Celan », Genesis [En ligne], 46 | 2018, mis en ligne le 01 juin 2019, consulté le 07 septembre 2019. URL : http:// journals.openedition.org/genesis/2606; DOI : 10.4000/genesis.2606 


\title{
Monolinguisme - plurilinguisme - translinguisme À propos de la genèse du poème "Huhediblu» de Paul Celan
}

\author{
Dirk Weissmann
}

\section{Paul Celan entre mono- et plurilinguisme}

De prime abord, définir la place du plurilinguisme dans l'œuvre du poète de langue allemande Paul Celan (1920-1970) est une tâche plutôt malaisée. Comme j'ai pu le montrer ailleurs ${ }^{1}$, on se trouve confronté, chez cet écrivain, à une contradiction - ou, du moins, à une tension - entre, d'une part, ses déclarations en faveur du monolinguisme en poésie («Le bilinguisme dans la poésie, je n’y crois pas», écrit-il notamment ${ }^{2}$ ) et d'autre part, une large panoplie de pratiques scripturales éminemment plurilingues. Or, plus que d'un poète écrivant en plusieurs langues, à l'instar d'un Rainer Maria Rilke ${ }^{3}$ ou d'un Stefan George ${ }^{4}$, il semble s'agir, dans le cas de Celan, d'un écrivain «post-monolingue», pour reprendre un concept proposé par Yasemin Yildiz, d'un poète qui, sans avoir laissé une œuvre en plusieurs langues, n'est pas non plus un écrivain purement monolingue, dans la mesure où il ne correspond pas à «l'idéal monolingue» tel qu'il a été forgé dans la tradition allemande5. D'autre part, même si Celan a pu prendre ses distances par rapport à des écrivains bilingues tels qu'Yvan Goll (implicitement visé par le propos cité6), ses propres poèmes, à l'instar de «Huhediblu » qui sera au centre de cette contribution, comportent des éléments hétérolingues issus de plusieurs autres langues ${ }^{7}$. Plus généralement, son parcours et ses activités littéraires sont profondément marqués par la pluralité de ses langues jusqu'à influer sur sa manière d'écrire des poèmes en allemand.

1. Voir mon article «Paul Celan's (M)Other Tongue(s): The Self Portrayal of the Artist as a Monolingual Poet», dans Juliane Prade (éd.), (M)Other Tongues: Literary Reflexions on a Difficult Distinction, Cambridge, Cambridge Scholars Publishing, 2013, p. 142-153. Voir également Ferdinand van Ingen, «Das Problem der lyrischen Mehrsprachigkeit bei Paul Celan», dans Joseph P. Strelka (dir.), Psalm und Hawdalah. Zum Werk Paul Celans, Berne, Peter Lang, 1987, p. 64-78; Hans-Peter Bayerdörfer, «,Sprachen Rag-time“? Überlegungen zur Entwicklung des polyglotten Gedichts nach $1945 »$, dans Dieter Breuer (dir.), Deutsche Lyrik nach 1945, Francfort/Main, Suhrkamp, 1988, p. 43-64; Gerhard Damblemont, «Mehrsprachige Autoren zur Einmaligkeit ihrer Dichtungssprache», dans Günther Holtus et Johannes Kramer (dir.), Das zweisprachige Individuum und die Mehrsprachigkeit in der Gesellschaft, Stuttgart, Steiner, 1991, p. 45-64.

2. Paul Celan, «Réponse à une enquête de la librairie Flinker, Paris (1961)», dans Le Méridien \& autres proses, édition bilingue, traduit et annoté par Jean Launay, Paris, Éditions du Seuil, 2002, p. 41.

3. Voir Eugenia Kelbert, «Reborn as René: The Interplay of Self and Language in a Selection of Rilke’s Late French and German Poems », The Yearbook of Comparative Literature, $\mathrm{n}^{\circ}$ 56, 2010, p. 201-224.

4. Voir mon article «Le paradoxe Stefan George, poète cosmopolite plurilingue et prophète de la renaissance nationale allemande», dans Britta Benert (dir.), Paradoxes du plurilinguisme littéraire 1900, réflexions théoriques et études de cas, Bruxelles, Peter Lang, 2015, p. 79-94.

5. Yasemin Yildiz, Beyond the Mother Tongue: The postmonolingual condition, New York, Fordham University Press, 2012 , p. 18 : « Celan [...] famously dismissed the notion of bilingualism in no uncertain terms and insisted on the singularity of the 'mother tongue' for his poetry [...]. Yet the configuration of this mother tongue differed significantly from the monolingual ideal: although German was the language he learned from and spoke with his beloved mother, it was not sanctioned by ethnic, religious, or national categories. In the end, it was also the language of his mother's murderers. At the same time, Celan was thoroughly multilingual in many ways: from his multilingual upbringing in Czernowitz and the fact that he never wrote in a purely monolingual German environment to his specific multilingual practices. Charting the tension between his monolingual assertion and his multilingual contexts and practices may illuminate his work in new way. In his case, voicing adherence to the monolingual paradigm may even be a case of resistance precisely because he is not supposed to fit into it. »

6. Les accusations de plagiat envers Celan ont été lancées par Claire Goll, la veuve d'Yvan Goll. Ce conflit aux effets dévastateurs sur le psychisme de Celan est omniprésent dans les propos de celui-ci au tournant des années 1960.

7. Pour le concept d'hétérolinguisme, je me réfère ici à l'étude de Myriam Suchet, L'Imaginaire hétérolingue. Ce que nous apprennent les textes à la croisée des langues, Paris, Classiques Garnier, 2014, qui aborde, en partie, l'œuvre de Celan. À l'origine, le terme a été introduit dans le débat par Rainier Grutman, Des langues qui résonnent. L'hétérolinguisme au XIXe siècle québécois, Montréal, Fides-CÉTUQ, 1997. 
Poète juif germanophone, d'origine roumaine et naturalisé français, installé à Paris de 1948 jusqu'à sa mort en 1970, Paul Celan a évolué tout au long de sa vie entre trois langues d'expression, l'allemand, le roumain, le français, complétées par bien d'autres langues à partir desquelles il a notamment traduit des œuvres d'autres poètes et écrivains : le russe, l'anglais, l'italien, l'hébreu, le portugais ${ }^{8}$. À examiner l'ensemble de la production de Celan, force est de constater que l'allemand est loin d'avoir été sa langue littéraire exclusive et que son œuvre recèle une diversité linguistique évidente : à côté de sa vaste œuvre de traducteur vers l'allemand ${ }^{9}$, il est l'auteur de traductions du russe vers le roumain 10 , ainsi que d'aphorismes et de proses poétiques écrites directement en roumain ${ }^{11}$. En outre, il existe de nombreux documents qu'il a écrits directement en français : notes, aphorismes, lettres ${ }^{12}$, un poème rédigé entièrement en français (dédié à son fils Éric13), des traductions et autotraductions, parfois déguisées ${ }^{14}$, vers le français, ainsi qu'une correspondance française très fournie avec son épouse Gisèle ${ }^{15}$.

Pour illustrer l'importance de la diversité linguistique chez Celan, on pourrait en outre évoquer ce qu'on peut désigner comme le patchwork linguistique de certaines notes qu'il a consignées dans ses cahiers pour accompagner sa création littéraire. Dans une entrée datée du 27 mars 1962, pour ne mentionner que cet exemple particulièrement probant, le poète passe - d'une manière tout à fait naturelle et spontanée - d'un idiome à l'autre, pour réunir quatre langues différentes en l'espace de quelques lignes : il y transcrit, en écriture cyrillique, un vers du poète russe Sergueï Essénine qu'il commente en français, en y glissant des extraits de sa traduction allemande, en même temps qu'il renvoie à Kafka, tout en enchaînant, dans la note suivante, avec une citation en latin ${ }^{16}$. Un tel procédé d'écriture n'est pas rare chez lui, y compris dans la genèse de ses poèmes, comme le montrera notamment le cas du poème «Huhediblu», écrit à peine six mois après les notes qu'on vient de citer, et issu du recueil Die Niemandsrose [La Rose de personne].

\section{Le plurilinguisme dans le recueil La Rose de personne}

Dans la plupart des cas cités plus haut, le plurilinguisme de Celan se manifeste au travers de documents non publiés.
Il faut reconnaître que, dans la production poétique publiée du vivant de Celan, cette diversité linguistique est loin d'être aussi évidente. Elle l'est d'autant moins qu'on sait que, vis-à-vis de son public, le poète a cultivé une image d'auteur exclusivement germanophone, une posture qui est inséparable de l'idée que son destin de poète juif, survivant de la Shoah, le liait irrémédiablement à la langue allemande ${ }^{17}$. Ce n'est que quand on accède aux archives du poète, en consultant les documents de sa période roumaine notamment, que la dimension éminemment plurilingue de ses activités éclate au grand jour. Toutefois, dans un certain nombre de cas, le qualificatif plurilingue pourrait également s'appliquer aux poèmes publiés ${ }^{18}$. Cela vaut en particulier pour les poèmes

8. Voir à cet égard le beau catalogue d'exposition sur l'œuvre de traducteur de Celan : Axel Gellhaus (dir.), «Fremde Nähe». Celan als Übersetzer, Marbach/Neckar, Deutsche Schillergesellschaft, 1997.

9. Traductions qui, selon les volontés de l'auteur, ont été incluses dans l'édition de ses œuvres complètes : Paul Celan, Gesammelte Werke in fünf Bänden, Francfort/Main, Suhrkamp, 1983. Les traductions en allemand occupent les volumes quatre et cinq de cette édition.

10. Voir Barbara Wiedemann, «Grischas Apfel und bitteres Staunen. Paul Celans Übertragungen ins Rumänische », Celan-Jahrbuch, $\mathrm{n}^{\circ} 5$, Heidelberg, Winter, p. 139-163.

11. Voir Paul Celan, «Mikrolithen sinds, Steinchen». Die Prosa aus dem Nachlaß, éd. Barbara Wiedemann et Bertrand Badiou, Francfort/Main, Suhrkamp, 2005, passim.

12. Paul Celan - René Char, Correspondance (1954-1968), éd. Bertrand Badiou, Paris, Gallimard, 2015; Bertrand Badiou, «..."vivant et redevable à la poésie" : le dialogue entre Paul Celan et André du Bouchet à travers

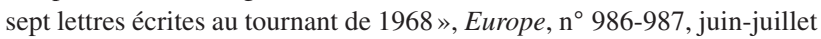
2011, p. 208-232.

13. Paul Celan, Die Gedichte aus dem Nachlass, éd. Bertrand Badiou, Jean-Claude Rambach, Barbara Wiedemann, Francfort/Main, Suhrkamp, 1997, p. 229.

14. Voir mon article «From Staged to Disguised Self-Translation: Heine and Celan in France», Arcadia, n ${ }^{\circ}$ 2, 2013, p. 436-445.

15. Paul Celan - Gisèle Celan-Lestrange, Correspondance (1951-1970), avec un choix de lettres de Paul Celan à son fils Éric, éditée et commentée par Bertrand Badiou, avec le concours d'Éric Celan, Paris, Éditions du Seuil, 2001, 2 vol.

16. Paul Celan, «Mikrolithen sinds, Steinchen», op. cit., p. 40.

17. Par rapport à cette problématique, voir notamment Enzo Traverso, «Paul Celan et la poésie de la destruction», dans L'Histoire déchirée. Essai sur Auschwitz et les intellectuels, Paris, Éditions du Cerf, 1997, p. $145-165$

18. À ce sujet, voir également Elizabeth Petuchowski, «Bilingual and Multilingual Wortspiele in the Poetry of Paul Celan», Deutsche Vierteljahresschrift, ${ }^{\circ} 52,1978$, p. 635-651. 
réunis dans le recueil Die Niemandsrose où l'on peut déceler la présence d'un grand nombre de langues étrangères.

Ce chef-d'œuvre poétique ${ }^{19}$, datant de 1963 et publié en traduction française en 197920 , occupe une position singulière au sein de l'œuvre de Celan, en incarnant un «tournant et un sommet» de sa poésie 21 . Ce recueil est également celui où la rencontre entre les langues atteint son apogée dans sa poésie, en multipliant le recours aux langues étrangères et aux procédés translingues. On peut y trouver des éléments hétérolingues provenant du français, de l'anglais, du latin, du yiddish, du russe, de l'hébreu. La Rose de personne est ainsi le recueil auquel s'appliquent le mieux ces propos de Jacques Derrida résumant admirablement la tension paradoxale évoquée au début de cette contribution : «Celan, ce poète-traducteur qui, écrivant dans la langue de l'autre et de l'holocauste, inscrivant Babel dans le corps même de chaque poème, revendiqua pourtant expressément, signa et scella le monolinguisme poétique de son œuvre 22 ».

En suivant ces propos, la revendication du monolinguisme cohabite donc chez Celan avec une écriture «inscrivant Babel dans le corps même de chaque poème», une pratique littéraire qui se situe dans une zone de contact entre plusieurs langues. À cet égard, le terme de translingue, employé dès le titre de cette contribution, n'est pas à concevoir comme un simple synonyme de plurilingue 23 . La différence entre les deux préfixes n'est pas arbitraire et comporte, à mon sens, une nuance importante. En effet, plus que d'une simple juxtaposition de plusieurs langues au sein d'un même texte, il s'agit en l'occurrence de processus d'écriture où les langues se rencontrent pour s'influencer, se traduire, s'hybrider mutuellement. Ce sont des phénomènes qui, se déroulant entre différentes langues, me semblent mieux désignés par le préfixe trans- que par celui de multi-, qui peut avoir un sens purement additif.

Nombre de poèmes de la Rose de personne s'inscrivent dans cette transversalité entre les langues dans la mesure où ils sont créés à partir d'un espace interlinguistique à plusieurs dimensions. Certains textes du recueil, comme «Benedicta 24 », «Anabasis 25 » ou «In Eins ${ }^{26}{ }$ » comportent d'importants éléments en langues étrangères; d'autres, comme «Bei Wein und Verlorenheit 27 », recourent à des tropes particuliers tels que la paronomase translingue ${ }^{28}$, en tissant un véritable réseau entre langues, où le sens du poème ne se construit que par l'entrelacement des différents niveaux de lecture en fonction des langues en jeu. C'est également le cas du poème «Huhediblu 29 » qui, issu d'une genèse textuelle translingue, est un exemple privilégié du plurilinguisme du recueil La Rose de personne. Dans ce qui suit, il s'agit de démontrer le rôle fondamental du plurilinguisme lors de la création de ce texte, plurilinguisme manifeste dès les brouillons et jusqu' au poème publié, afin de faire ressortir les procédés translingues qui ont guidé son écriture.

\section{Le plurilinguisme du poème «Huhediblu»}

Écrit en septembre 1962 en Normandie, le poème «Huhediblu» est l'un des textes les plus manifestement plurilingues de Celan. La version publiée du poème comporte en effet nombre d'éléments hétérolingues issus du français, de l'anglais, du latin et de différentes variétés de l'allemand. Voici le texte allemand, l'objet des analyses qui suivent, accompagné de la traduction française, qui n'est donnée qu'à titre informatif (encadré ci-dessous).

À l'instar de la traduction de la plupart des textes mélangeant plusieurs langues, la traduction française provoque ici une réduction dommageable de la dimension plurilingue du poème, un aplanissement linguistique. La traduction française d'un texte allemand recourant massivement

19. Paul Celan, Die Niemandsrose, Francfort/Main, Fischer, 1963.

20. Paul Celan, La Rose de personne, trad. Martine Broda, Paris, Le Nouveau Commerce, 1979.

21. Jürgen Lehmann (éd.), Kommentar zu Paul Celans «Die Niemandsrose », Heidelberg, Winter, 2003, p. 7. Voir aussi le bel essai de Martine Broda, Dans la main de personne, Essai sur Paul Celan, Paris, Éditions du Cerf, 1986

22. Jacques Derrida, Le Monolinguisme de l'autre, ou la prothèse de l'origine, Paris, Galilée, 1996, p. 129-130.

23. Pour la définition du terme de translingue, voir Steven G. Kellman, The Translingual Imagination, Lincoln/Londres, University of Nebraska Press, 2000. Pour la discussion terminologique, voir la contribution d'Olga Anokhina et Emilio Sciarrino ici-même.

24. Paul Celan, Gesammelte Werke, op. cit., vol. I, p. 249-250.

25. Ibid., p. 256-257.

26. Ibid., p. 270.

27. Ibid., p. 213.

28. Ce procédé est notamment analysé par Myriam Suchet, L'Imaginaire hétérolingue, op. cit., p. 134, qui cependant parle simplement d' «homographie».

29. Paul Celan, Gesammelte Werke, op. cit., vol. I, p. 275-277. 


\section{HUHEDIBLU*}

Schwer-, Schwer-, Schwer-

fälliges auf

Wortwegen und -schneisen.

Und - ja -

5 die Bälge der Feme-Poeten

lurchen und vespern und wispern und vipern,

episteln.

Geunktes, aus

Hand- und Fingergekröse, darüber

10 schriftfern eines

Propheten Name spurt, als

An- und Bei- und Afterschrift, unterm

Datum des Nimmermenschtags im September - :

Wann,

15 wann blühen, wann,

wann blühen die, hühendiblüh,

huhediblu, ja sie, die September-

rosen?

Hüh - on tue... Ja, wann?

20 Wann, wannwann,

Wahnwann, ja Wahn,

Bruder

Geblendeter, Bruder

erloschen, du liest,

25 dies hier, dies :

Dis-

parates - : Wann

blüht es, das Wann,

das Woher, das Wohin und was

30 und wer

sich aus- und an- und dahin- und zu sich lebt, den

Achsenton, Tellus, in seinem

vor Hell-

hörigkeit schwirrenden

35 Seelenohr, den

Achsenton tief

im Innern unsrer

sternrunden Wohnstatt Zerknirschung? Denn

sie bewegt sich, dennoch, im Herzsinn.

40 Den Ton, oh

den Oh-Ton, ah,

das $\mathrm{A}$ und das $\mathrm{O}$,

das Oh-diese-Galgen-schon-wieder, das Ah-es-gedeiht,

\section{FLHUERISSENTLES}

Lourd-, lourd-, lour-

daudement sur

les chemins et les layons des mots

Et - oui -

les baudruches des poètes proscripteurs

vipèrent, vespèrent et vitupèrent, grenouillent,

épistolent.

Bave de crapaud, ou

tripe de main et de doigt, dans laquelle

loin de l'Écriture

le nom du prophète laisse sa trace, comme

agresse, commenteur, et post-hume post-face, datée

du jour de personne en septembre - :

Quand,

quand fleurissent, quand

quand fleurissent les,

flhuerissentles, oui, les

roses de septembre?

Hue - on tue... Mais quand?

Quand, cancan,

où, fou, oui, fou -

frère

Aveuglé, frère,

Éteint, tu lis

ceci, oui, ici :

dis-

parate - : quand

fleurit-il, le quand,

le d'où, le vers-où, et cela

et celui

qui vit à fond, à peine, à perte, à soi revit, le

ton axial, Tellus, dans

l'oreille de son âme

vibrant de clair-

audience, le

ton axial tout

au fond de notre

demeure Contrition, ronde comme une étoile. C'est qu'elle tourne, pourtant, dans le sens du cœur.

Le ton, oh,

le oh-ton, ah

le a et le o

le oh-encore-ces-gibets, le ah-comme-ça-pousse-bien, 
auf den alten

45 Alraunenfluren gedeiht es,

als schmucklos-schmückendes Beikraut,

als Beikraut, als Beiwort,

als Beilwort,

ad-

50 jektivisch, so gehn

sie dem Menschen zuleibe, Schatten,

vernimmt man, war

alles Dagegen -

Feiertagsnachtisch, nicht mehr, - :

55 Frugal,

kontemporan und gesetzlich

geht Schinderhannes zu Werk,

sozial und alibi-elbisch, und

das Julchen, das Julchen:

60 daseinsfeist rülpst,

rülpst es das Fallbeil los, — call it (hott!)

love.

Oh quand refleuriront, oh roses, vos septembres? ça pousse,

sur les vieux champs de mandragores,

herbe superfétatoire

épice, épithète, ou

mot coupe-tête,

ad-

jectivement,

ils s'attaquent à l'homme, ombre,

dit-on, était

tout remède -

rien d'autre qu'un dessert de fête - :

Frugal,

contemporain et dans la loi,

Schinderhannes se met au travail,

social et alibi-elbique, et

la Juliette, sa Juliette,

elle rote, obèse d'exister,

pour déclencher la guillotine, - call it (hott!)

love.

Oh quand refleuriront, oh roses, vos septembres?

(*) Paul Celan, La Rose de personne, op. cit., p. 122-127; la traduction de Martine Broda a été légèrement modifiée par mes soins.

au français pose de toute évidence des problèmes quasi insolubles. Néanmoins, Martine Broda, qui reste - à ma connaissance - la seule à avoir traduit en français ce texte hautement difficile, a effectué un travail admirable qui, par certains aspects, éclaire le texte original ${ }^{30}$.

Au niveau du plurilinguisme, la version publiée du poème frappe d'abord par la présence de deux importants éléments en français renvoyant au point de départ de sa genèse. Il s'agit, premièrement, d'un vers français extrait d'un poème de Verlaine, «L'espoir luit», issu de son recueil Sagesse (1880) ${ }^{31}$. Ce vers («Ah! quand refleuriront les roses de septembre»), modifié profondément par Celan, clôt le poème (v. 63), mais on verra que, tronqué, réécrit, traduit, il informe en réalité l'intégralité de sa genèse. Le deuxième élément, le verbe français «tuer», apparaissant au vers 19 , renvoie pour sa part à l'autre intertexte matriciel de «Huhediblu», le poème «Schinderhannes » issu d'Alcools d'Apollinaire (1913) ${ }^{32}$. Aux côtés du motif verlainien de la floraison (des roses), cette citation s'intègre dans un complexe tissu translingue constitué des mots «fleurir/blühen» et «tuer/töten», ainsi que d'un ensemble de morphèmes hybrides : «hue(r)/hü/(b)uhen ${ }^{33} »$. On peut noter au passage que ces deux poèmes de Verlaine et d'Apollinaire ont par ailleurs été traduits par Celan ${ }^{34}$.
S'y ajoute une troisième citation hétérolingue, en langue anglaise (v. 61-62), elle aussi modifiée par Celan : le titre d'un poème quasi contemporain du poète allemand Hans Magnus Enzensberger, «Call it love 35 !». On a donc affaire, en l'occurrence, à un hypotexte qui lui-même est

30. Voir infra fig. 3.

31. Paul Verlaine, CEuvres poétique complètes, éd. Yves-Gérard Le Dantec et Jacques Borel, Paris, Gallimard, coll. «Bibliothèque de la Pléiade», 1938, p. 274.

32. Guillaume Apollinaire, Euvres poétiques complètes, éd. Marcel Adéma et Michel Décaudin, Paris, Gallimard, coll. «Bibliothèque de la Pléiade», 1956, p. 117-118. Celan reprend notamment la strophe finale du poème : «On mange alors toute la bande/Pète et rit pendant le dîner/ Puis s'attendrit à l'allemande/Avant d'aller assassiner ».

33. Voir infra fig. 3.

34. La traduction du poème d'Apollinaire a été publiée en 1954 ; elle figure dans Paul Celan, Gesammelte Werke, op. cit., vol. IV, p. 786-789. La traduction du poème de Verlaine, datant de la jeunesse de Celan, à Czernowitz, n'a jamais été publiée par l'auteur. Le sort réservé, dans «Huhediblu», au vers final du poème verlainien n'est sans doute pas étranger au gouffre historique et biographique qui sépare l'avant et l'après de la Shoah. Voir Barbara Wiedemann, «Im alten Garten - Septemberrosen. Noch einmal zu Paul Celan und Paul Verlaine», Celan Jahrbuch, ${ }^{\circ} 5$, 1993, p. 279-292, qui reproduit l'intégralité de cette traduction.

35. Hans Magnus Enzensberger, «Call it love», dans Verteidigung der Wölfe, Francfort/Main, Suhrkamp, 1957, p. 21. 
déjà plurilingue. De surcroît, Celan complète cette citation anglaise par un élément polysémique instaurant une relation translingue entre l'anglais «hot (love)», l'allemand «(hüh) hott», mais aussi, par effet de paronomase, le français «hotte» dans le sens de cheminée, ce qui renvoie, par référence indirecte, à la Shoah et au thème de la tuerie aux accents antisémites chez Apollinaire (v. 57) ${ }^{36}$. À partir de ces premiers éléments, qu'il s'agira d'approfondir par la suite, on voit que le plurilinguisme du poème repose d'abord sur une forme complexe d'intertextualité hétérolingue.

Ces éléments français et anglais, se détachant de la langue dominante allemande, sont complétés par des mots qui, sans être proprement hétérolingues, renforcent l'impression générale d'hybridité linguistique qui se dégage du texte : des mots à racine latine apparente («episteln», v. 7, «Dis-/parates», v. 26-27, «Tellus», v. 32, «frugal», v. 55, «kontemporan», v. 56), des variantes diastratiques et diaphasiques, «sozial», v. 58, («rülpst», v. 60-61), ainsi qu'un certain nombre d'onomatopées, dont l'interjection «hüh» (v. 19) se trouvant à la base de plusieurs créations lexicales (v. 16-17), y compris du titre «Huhediblu», qui est un hapax linguistiquement hybride, comme on le verra plus loin.

Dans l'ensemble, le plurilinguisme du poème s'inscrit dans le cadre d'une prodigieuse et puissante inventivité verbale (moyennant onomatopées, allitérations, assonances, métathèses, métaplasmes, paronomases, intertextes, etc.) qu'il n'est pas possible d'analyser intégralement dans la présente contribution ${ }^{37}$. Pas plus qu'il n'est possible de fournir une explication ou un commentaire exhaustifs de ce texte. Toutefois, avant d'approfondir l'analyse de la dimension plurilingue de «Huhediblu», je vais tâcher de proposer une sorte d'interprétation minimale du poème.

\section{Commentaire succinct du poème}

Paul Celan est connu pour être un poète $d$ 'accès difficile dont les textes ont souvent été qualifiés d'hermétiques. C'est une idée controversée, voire contestable, mais qui n'est pas complètement erronée compte tenu du fait qu'un nombre important de ses poèmes est truffé d'allusions, de références historiques, d'intertextes, de biographèmes, etc. Quoi qu'il en soit, il serait assurément illusoire, dans le cadre de la présente contribution, axée sur la dimension plurilingue du texte, de prétendre en fournir une interprétation détaillée. Néanmoins, afin d'apprécier à leur juste valeur la présence d'autres langues dans le texte, il est indispensable, après ce premier état des lieux en matière de plurilinguisme, de fournir au lecteur quelques éléments de compréhension qui donneront les clés pour une interprétation minimale du poème.

Sans faire partie des poèmes les plus célèbres de l'auteur, «Huhediblu» est sans doute l'un des textes les plus importants de Die Niemandsrose. Il contient d'ailleurs le motif central de ce recueil, la rose, et plusieurs références à son dédicataire, le poète russe Ossip Mandelstam ${ }^{38}$. Il s'agit d'un texte d'une grande fulgurance poétique qui associe une certaine violence verbale, la gravité de son propos, au ludisme langagier, sous forme de jeux de mots, en conjuguant des thèmes existentiels et tragiques avec l'esprit du calembour et avec une musicalité qui peut rappeler la poésie lettriste. C'est un poème qu'on pourrait d'abord interpréter comme l'expression d'un profond abattement devant les difficultés existentielles provoquées par la dure tâche de l'écriture poétique (le poème s'ouvre sur l'idée de la «lourdeur» des mots, v. 1-3). Plus généralement, il peut se lire comme l'expression d'une grave crise personnelle, se vérifiant dans la biographie de Paul Celan ${ }^{39}$.

\section{Voir infra fig. 3}

37. Le commentaire le plus exhaustif du poème est fourni par Ulrich Konietzny, «[commentaire de] Huhediblu », dans Jürgen Lehmann (éd.), Kommentar zu Paul Celans «Die Niemandsrose», op. cit., p. 295-419. Voir aussi le commentaire, plus actuel, de Barbara Wiedemann dans son édition des œuvres poétiques complètes: Paul Celan, Die Gedichte, Kommentierte Gesamtausgabe in einem Band, éd. B. Wiedemann, Francfort/Main, Suhrkamp, 2003, p. 705-707. À ma connaissance, il n'existe aucun commentaire ou interprétation détaillés en langue française. Mais le lecteur non germanophone pourra utilement consulter l'article d'Hermann H. Wetzel, «Verlaine et les poètes de langue allemande », dans Pierre Brunel et André Guyaux (dir.), Paul Verlaine, Paris, Presses de l'université Paris-Sorbonne, 2004, p. 132-149. Les pages 142-148 contiennent un commentaire instructif du poème de Celan. 38. Le prénom de Mandelstam apparaît dès le premier brouillon; dans la version publiée, il est présent dans l'apostrophe «Bruder» (v. 23) et à travers le mot «Achsenton» (v. 36), voir Konietzny, op. cit., p. 301-302. 39. En 1960, Celan reçut le prix Büchner, le plus important prix du monde littéraire allemand; à la même époque, les accusations de plagiat, lancées par la veuve d'Yvan Goll et relayées par la presse, ont provoqué chez lui une profonde détresse psychique. D'après les documents et témoignages dont on dispose, Celan se sentait rejeté, voire persécuté, malgré la reconnaissance et le renom dont il jouissait objectivement. À partir de fin 1962, il fit plusieurs séjours en hôpital psychiatrique. Son état psychique allait en s'aggravant jusqu'à son suicide en 1970. 
Écrit sous l'effet des accusations (infondées) de plagiat lancées contre son auteur, le poème semble évoquer un contexte hautement conflictuel, l'adversité d'un public et d'une critique, en Allemagne et au-delà, qui - selon le poète - ne loue son art que pour mieux l'attaquer, le diffamer, le détruire ${ }^{40}$. À travers ce texte, le poète semble évoquer ses relations difficiles avec la scène littéraire allemande et exprimer ses craintes face à la résurgence de l'antisémitisme à cette époque. Les deux aspects étant réunis dans les accusations de plagiat, connues sous le nom d' «affaire Goll»41, une querelle littéraire relayée par une presse conservatrice et par des critiques connus pour leurs accointances avec le régime nazi ou dont les positions s'inscrivaient dans le droit fil de l'idéologie de ce dernier.

Le thème du langage, au cœur du poème, renvoie non seulement au dur métier de poète (partie médiane du poème) et aux difficultés pour un survivant de la Shoah d'écrire des poèmes en allemand, mais il accuse un certain langage, une certaine langue allemande, d'être solidaire avec les assassins, de tuer à sa manière (v. 4-13 et partie finale). Cette idée du langage meurtrier, fréquente dans l'œuvre de Celan, se trouve condensée par le néologisme de «mot coupe-tête/Beilwort» (v. 48); il apparaît aussi, dans un mélange d'allemand et de français, au vers 19 , sous forme de rime translingue : «Hüh - on tue... ${ }^{42}$ ». En réalité, cette association entre le langage et l'assassinat, entre la poésie et la mort, est présente d'entrée de jeu, dans la mesure où le titre «Huhediblu», hapax ou barbarisme créé à partir d'un idiome hybride franco-allemand, renvoie à la fois à «fleurir/blühen» (comme allégorie de la poésie), à «hue(r)/ $h \ddot{\prime} /(b) h e n »$ et à «tuer». Tout au long du texte, la menace ainsi évoquée, sous la forme d'un présent d'actualité («on tue»), est soulignée par la lancinante question du «quand/ $W_{a n n}{ }^{43}$ », qui non seulement pointe le retour (possible, probable, imminent) des assassins, mais fait également référence au passé antisémite et génocidaire 44 .

\section{Les brouillons plurilingues du poème}

Comme on vient de le voir, le poème «Huhediblu» est d'une complexité redoutable; il peut donner lieu à des interprétations d'ordre biographique, historique, linguistique... Cependant, l'objectif de cette contribution étant d'analyser la genèse translingue du texte, en s'intéressant notamment au plan formel, il est temps, à présent, d'examiner le plurilinguisme à travers les différentes étapes de la création du poème et, par conséquent, dans les différents états génétiques du texte. Même si cette approche purement génétique implique de laisser de côté un certain nombre d'autres aspects du texte, elle permettra de faire apparaître le cœur ou la colonne vertébrale du poème, pour recourir à des métaphores issues du domaine de l'anatomie.

Si la version publiée apporte en soi un démenti au monolinguisme revendiqué (au moins en apparence) par Celan, la dimension plurilingue du poème s'avère être plus marquée encore dans ses versions préparatoires. Il se trouve en effet que le poème est pour ainsi dire né en marge d'extraits de poèmes français de Verlaine et d'Apollinaire, cités plus haut, sans oublier le titre anglais d'Enzensberger. Il s'agit de vers en langue étrangère qui constituent la matrice de la genèse et dont on peut suivre la trame de la première ligne du premier jet jusqu'à la version finale de ce poème, en passant par le titre emblématique, qui condense les particularités formelles mais aussi le thème essentiel du poème.

Grâce à la place singulière de l'œuvre de Paul Celan dans l'histoire de la littérature allemande depuis 1945, nous disposons de pas moins de deux éditions génétiques de son œuvre poétique, publiées de surcroît chez le même éditeur. La première de ces éditions, dite «édition de Bonn», commencée au lendemain de la mort du poète, présente, sous forme de transcriptions diplomatiques, la totalité des

40. Voir à cet égard la lettre de Celan à Alfred Margul-Sperber citée dans Jürgen Lehmann, op. cit., p. 12, et la lettre à Erich Einhorn citée par B. Wiedemann dans Paul Celan, Die Gedichte, op. cit., p. 707.

41. Pour une documentation complète de l'affaire du plagiat, voir l'ouvrage de référence de Barbara Wiedemann (dir.), Paul Celan - Die GollAffäre. Dokumente zu einer "Infamie », Francfort/Main, Suhrkamp, 2000. 42. Le «Hüh! » allemand étant un homophone de «hue!» en français, les deux langues ne se différencient en l'occurrence que par la graphie. 43. Hermann H. Wetzel, op. cit., p. 146, interprète ce passage comme l'expression de l'effort répété «pour réussir à déclamer la traduction du vers de Verlaine, - effort voué à l'échec sous le choc d'une expérience vécue de la terreur nazie -, sa langue se confond tout à fait. »

44. Interprétation qui peut, entre autres, s'appuyer sur la proximité entre le pronom interrogatif «Wann» (quand) et le nom de la tristement célèbre conférence de Wannsee où fut décidée la «solution finale». Voir infra fig. 3 . 
$\begin{array}{llllllll}\text { G } & \text { E } & \text { N } & \text { E } & \text { S } & \text { I } & \text { S }\end{array}$

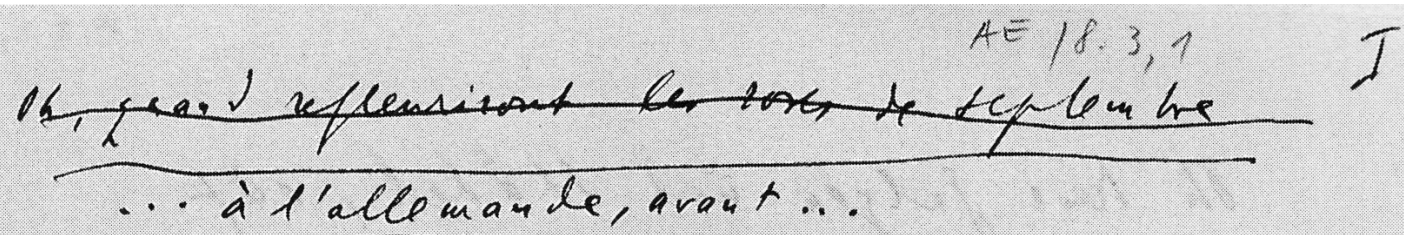

idver, shore, Schere-

fillife, a it

4n hregen. - rie

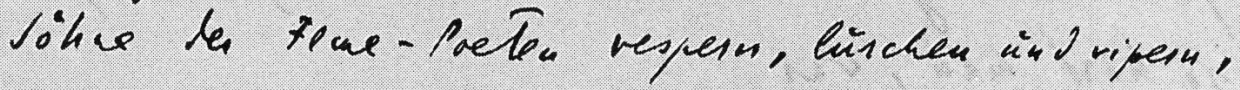
epintela. geainktes, wa linbla, Puatit me hame Samice quart, elo Ma-sdrif

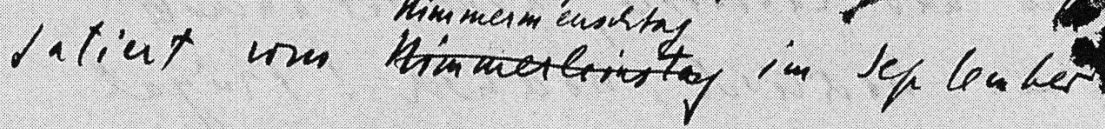

- erace Haken, vann,

nuabla'kerkè, nuntlikeusichabi

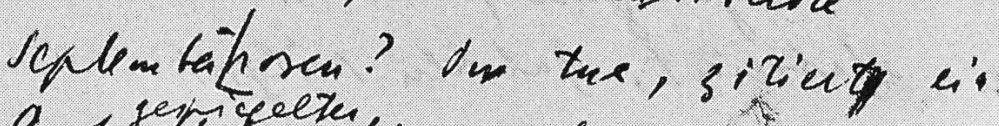

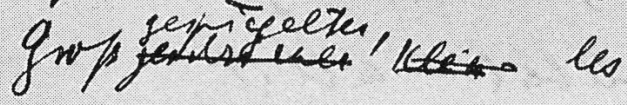

Iux, bes

wites pous

les citer apiès wana? Hahnaram, Wan, tans,

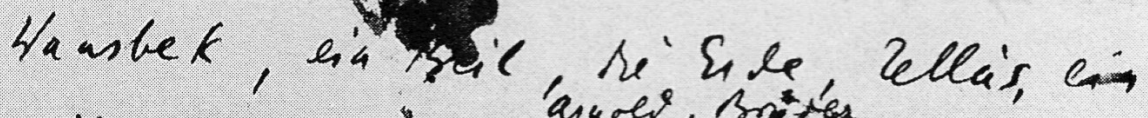

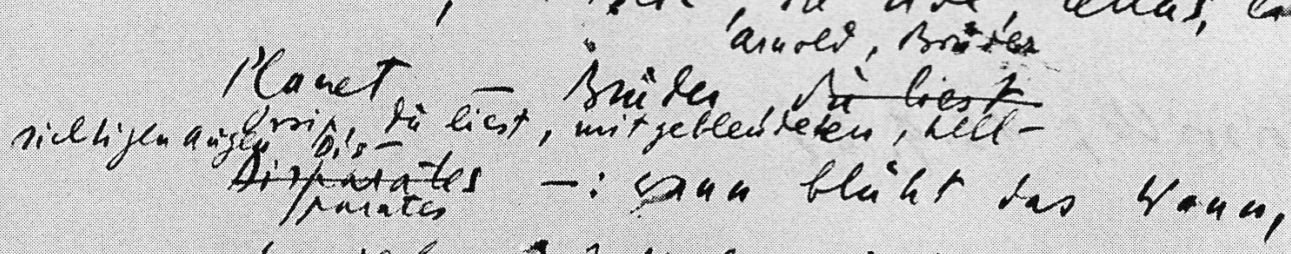

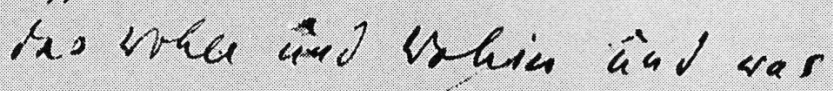

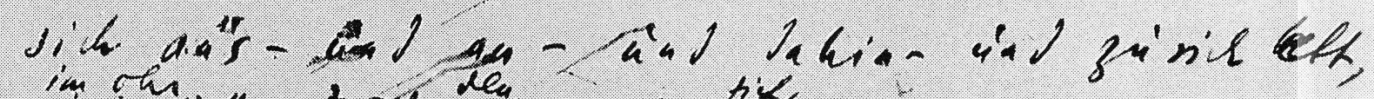

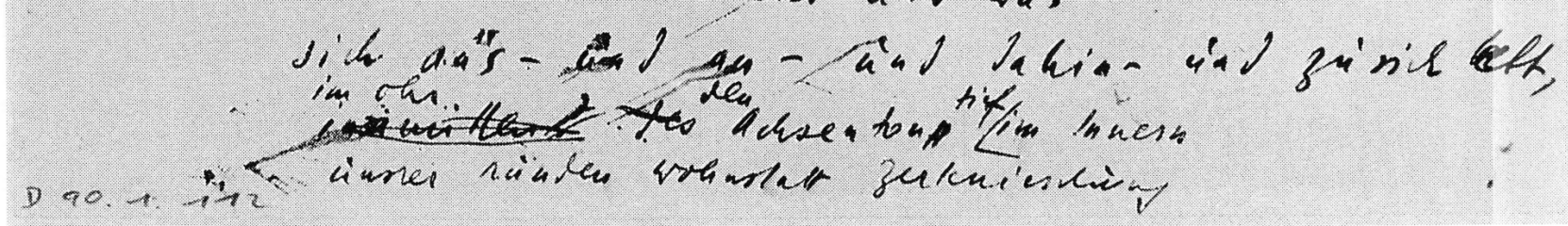

Fig. 1 : Fac-similé du premier feuillet recto des brouillons du poème «Huhediblu» (H6).

Document répertorié par les responsables de l'édition génétique sous la cote AE 8.3,1 et reproduit dans les annexes de l'édition de Tübingen, op. cit.

Publié avec l'aimable autorisation d'Éric Celan et du Deutsches Literaturarchiv Marbach (cote d'archive : D.90.1.112).

Genesis 46.indb 42

$28 / 05 / 2018 \quad 13: 00$ 
MONOLINGUISME_-PLURILINGUISME_- TRANSLINGUISME

\begin{tabular}{llllll} 
É & T & U & D & E & S \\
\hline
\end{tabular}

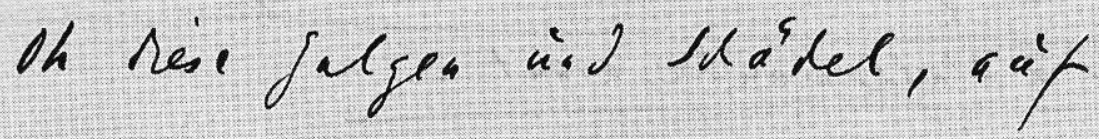
Aliacien flivea jeleikt

Is gogielrasichate bainst, al-

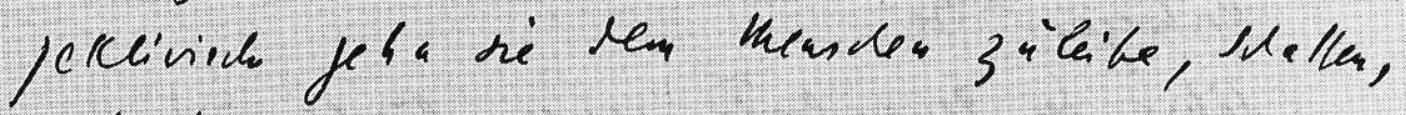
so hiot man, ven

elles dajeger jeletre - Irnf-

kolonica aq J la.bingle, litte iss "a"che te

orf -: Heatiss, noction ! Fingal

ji, I de keakenmable am Main, Kon-

temporan ais jextgure, Minta-

haunes slatieint, judren 1iejpot

exilenticle. Jas Fallbil - all it

lone. -

it quand refensiont, \& coses, wos seplentres?

moiuntle, 13.9.6?

Fig. 2 : Fac-similé du premier feuillet verso des brouillons du poème «Huhediblu» (H6).
Document répertorié par les responsables de l'édition génétique sous la cote AE 8.3,1 et reproduit dans les annexes de l'édition de Tübingen, op. cit.
Publié avec l'aimable autorisation d'Éric Celan et du Deutsches Literaturarchiv Marbach (cote d'archive : D.90.1.112).

Publié avec l'aimable autorisation d'Éric Celan et du Deutsches Literaturarchiv Marbach (cote d'archive : D.90.1.112). 
brouillons conservés 45 , en documentant toutes les étapes de la genèse de l'œuvre. Dans le cas du poème «Huhediblu», il s'agit de sept documents qui en composent le dossier avant-textuel 46

La deuxième édition, dite «édition de Tübingen», sans différer radicalement de sa concurrente, mise davantage sur le réalisme topographique et sur la lisibilité de la transcription, au prix de certaines simplifications; elle opère ainsi un choix de trois brouillons parmi l'ensemble des documents conservés, en les imprimant, intégralement et de manière synoptique, côte à côte, ce qui permet d'embrasser d'un seul coup d'œil plusieurs états génétiques du texte. Dans le cas de «Huhediblu», étant donné le nombre réduit de brouillons conservés, cette sélection permet de retracer aisément les principales étapes de sa genèse, en reproduisant le plus fidèlement possible la disposition spatiale et la nature graphique du texte ${ }^{47}$. En outre, chaque volume de l'édition de Tübingen est accompagné de plusieurs fac-similés dont celui du premier manuscrit de «Huhediblu», daté du 13 septembre 1962 (voir fig. 1 et 2).

Dans l'ensemble, ce riche matériau - les deux éditions critiques et leurs transcriptions, complétées par le fac-similé du premier brouillon (fig. 1 et 2) - permet donc de suivre avec précision les étapes de la genèse du poème «Huhediblu», pour analyser notamment la manière dont les multiples langues du texte, principalement l'allemand, le français et l'anglais, interagissent pour aboutir au titre étrange, hybride, translingue du poème. En effet, ce titre, réunissant tous les fils et toutes les langues ayant participé à la création du poème, s'est fixé à un moment assez tardif du processus d'écriture, lorsque le texte était déjà très proche de sa version finale ${ }^{48}$. Autrement dit : la naissance du mot «Huhediblu» n'a été possible qu'à l'issue de toute une série de jeux entre les différentes langues en présence. De cette manière, le titre du poème semble représenter un point d'aboutissement, une forme de condensation extrême de sa genèse translingue.

Pour comprendre la manière dont ce poème est né «entre» plusieurs langues, il convient à présent de remonter au début du processus d'écriture, au premier brouillon (H6). Comme on peut le voir sans grande difficulté, à travers les transcriptions ou directement dans le fac-similé (fig. 1 et 2), ce premier manuscrit contient cinq séquences en langue étrangère dont trois citations facilement identifiables et une phrase dont la source est plus obscure : $1^{\circ}$ la citation d'un vers de «L'espoir luit» de Verlaine («Oh, quand refleuriront les roses de septembre», tout en haut de la première feuille);

$2^{\circ}$ la même citation mais profondément modifiée (tout en bas de la deuxième feuille, fig. 2);

$3^{\circ}$ la citation d'un extrait de «Schinderhannes » d'Apollinaire («... à l'allemande, avant...», tout en haut de la première feuille, fig. 1);

$4^{\circ}$ la citation du titre d'un poème de Hans Magnus Enzensberger («call it love», en bas de la deuxième feuille, fig. 2).

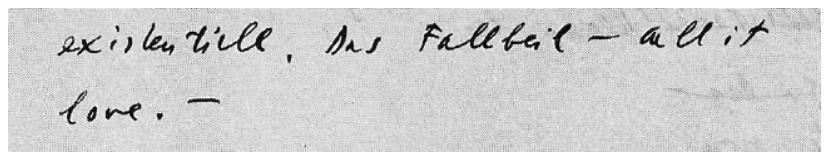

Fac-similé du premier feuillet verso des brouillons du poème «Huhediblu» (H6) (détail)

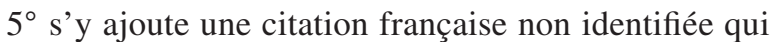
présente d'emblée plusieurs couches de réécriture, mais dont la forme d'origine semble bien être : «On tue les poètes / Pour les citer après 49 » (à partir du milieu de la première feuille, fig. 1)

45. Les archives Paul Celan sont conservées au Deutsches Literaturarchiv de Marbach, en Allemagne.

46. Paul Celan, Werke, Historisch-kritische Ausgabe, I. Abteilung: Lyrik und Prosa - Band 6: Die Niemandsrose (Bonner Ausgabe), éd. Axel Gellhaus, Francfort/Main, Suhrkamp, 2001, vol. 6.2 (appareil génétique), p. 248-258. L'édition de Bonn répertorie cinq brouillons plus deux épreuves d'imprimerie, formant la totalité des documents conservés, du premier jet (H6) jusqu'à la version publiée (D). Les documents désignés par H6 et $\mathrm{H} 5$ sont des manuscrits, H4-H2 sont des dactylographies, d1 et d désignent les épreuves. Parmi ces documents, l'édition de Tübingen reproduit seulement $\mathrm{H} 6, \mathrm{H} 5$ et $\mathrm{H} 3$, soit trois documents génétiques sur les cinq conservés (hors épreuves).

47. Paul Celan, Die Niemandsrose, Vorstufen - Textgenese - Endfassung (Tübinger Ausgabe), éd. Jürgen Wertheimer, Francfort/Main, Suhrkamp, 1996, p. 116-119.

48. Voir la transcription de la deuxième dactylographie $(\mathrm{H} 3)$ du poème dans l'édition de Tübingen, op. cit., p. 117. Voir aussi la note indiquant que la table du recueil mentionnait longtemps un titre différent, ce qui semble confirmer que le titre reflète un long cheminement.

49. Je m'en tiens ici à une transcription conjecturale très simplifiée de cette citation; pour une transcription intégrale voir les deux éditions op. cit. D'après ses propres affirmations, Celan aurait lu ces vers chez un «poète russe», mais la source n'a jamais pu être retrouvée (voir le commentaire 


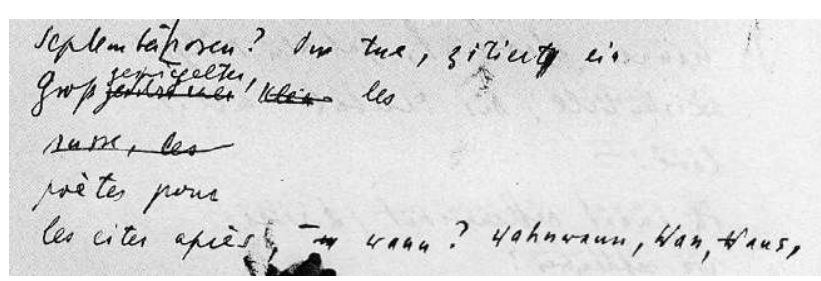

Fac-similé du premier feuillet recto des brouillons du poème «Huhediblu» (H6) (détail)

Transcription :

On tue $[\ldots]$ les russes, les

poètes pour les citer après

Dans l'ensemble, on peut ici parler d'une «appropriation transformatrice 50 » des hypotextes, procédé généralisé dans le recueil La Rose de personne (et au-delà) grâce auquel le poète traduit, modifie et complète ces matériaux. Ainsi, le vers de Verlaine est biffé et déplacé, sous une forme profondément transformée, à la fin de cette première ébauche : «Oh quand refleuriront, oh roses, vos septembres $\left(^{(v . ~ 63)}{ }^{51}\right.$. Le titre d'Enzensberger se voit pour sa part affublé, dès le deuxième manuscrit $(\mathrm{H} 5)$, du qualificatif «hott 52 ». Quant à l'extrait littéral du poème d'Apollinaire, il disparaîtra durant la genèse pour rester présent notamment sous la forme de certains noms propres («Schinderhannes», v. 57; « Julchen», v. 59)53, et, surtout, sous forme du thème de la tuerie (teintée d'antisémitisme) qui constitue le contexte immédiat de cette citation ${ }^{54}$. Il entretient ainsi un lien intime avec la citation française non identifiée du brouillon ( «On tue les poètes...»).

On voit ici que cette appropriation est non seulement transformatrice mais qu' elle comporte une dimension qu'on pourrait qualifier de critique, voire de polémique. Le titre d'Enzensberger, travesti moyennant un ajout lourd de sens, renvoie ainsi au thème des assassinats 55 , ce qui pourrait s'interpréter comme un règlement de compte avec ce poète contemporain de Celan 56 . Le beau vers de Verlaine est supprimé, déplacé, chamboulé, puis disséminé sous forme de traduction fragmentaire (voir notamment le motif récurrent du «Wann...», v. 14-28, issu du «Oh quand...57», et les «Septemberrosen», v. 17-18) . En outre, le lyrisme verlainien, son habile musicalité, mais aussi l' «espoir» qu'il entend communiquer, se voient questionnés par le poème 58 , la citation raturée étant remplacée par le thème de la lourdeur verbale, du balbutiement : «Schwer-, Schwer-,
Schwer- /fälliges », v. 1-2, présent dès le premier brouillon avant de devenir la première strophe du poème publié59 Concernant la référence à Apollinaire, elle est masquée,

de B. Wiedemann dans Die Gedichte, Kommentierte Gesamtausgabe, op. cit., p. 706). Par la reprise, en français (!), de ce vers, Celan semble actualiser le mythe du poète maudit, en l'appliquant à sa propre situation au début des années 1960 . On pourrait à cet égard notamment penser à l'incipit du fameux poème «Смерть поэта / La mort du poète » écrit par Lermontov en réaction à la mort de Pouchkine, tué en duel : « Погиб поэт! - невольник чести - Пал, оклеветанный молвой [...] / Le poète est mort, de l'honneur esclave; / Diffamé par l'opinion [...]», des vers qui résonnent très fort avec l'affaire du plagiat et ses conséquences sur le psychisme de Celan, poète célébré, mais qui avait l'impression qu'on était en train de l'assassiner par la voie d'une infâme diffamation. Sur le lien entre «Huhediblu » et l'affaire Goll voir le commentaire de B. Wiedemann dans Paul Celan, Die Gedichte, Kommentierte Gesamtausgabe, op. cit., p. 707. Plus généralement, voir aussi B. Wiedemann (éd.), Paul Celan Die Goll-Affäre, op. cit.

50. Jürgen Lehmann, op. cit., p. 28.

51. Paul Celan, Tübinger Ausgabe, op. cit., p. 116-118/Bonner Ausgabe, op. cit., p. 249-250.

52. Paul Celan, Tübinger Ausgabe, op. cit., p. 118/Bonner Ausgabe, op. cit., p. 253.

53. Paul Celan, Tübinger Ausgabe, op. cit., p. 116-119/Bonner Ausgabe, op. cit., p. 249-258.

54. Voici les vers qui entourent l'extrait cité par Celan : «Puis s'attendrit à l'allemande / Avant d'aller assassiner». Schinderhannes (Johann Bückler) est un célèbre brigand ayant semé la terreur dans la région du Rhin aux alentours de 1800 . Le poème d'Apollinaire comporte aussi ce vers hautement intéressant dans le contexte thématique du texte de Celan : «Il faut ce soir que j' assassine / Ce riche juif au bord du Rhin», op. cit. Chez Apollinaire, et plus encore chez Celan, l'image de Schinderhannes n'est pas celle d'un Robin des Bois allemand, mais celle d'un assassin, violent, débauché, antisémite. Sur le lien entre le poème d'Apollinaire et l'affaire Goll voir le commentaire de B. Wiedemann dans Paul Celan, Die Gedichte, Kommentierte Gesamtausgabe, op. cit., p. 707.

55. Celan ne se limite pas à ajouter un mot anglais à une citation en anglais. Le dédoublement graphique de la consonne « $\mathrm{t}$ » établit un lien au «Hüh - on tue» en même temps que «hott» peut se lire comme une paronomase du français «hotte» dont la fumée potentielle renvoie aux camps de la mort.

56. Voir Myriam Suchet, Outils pour une traduction postcoloniale. Littératures hétérolingues, Paris, Éditions des archives contemporaines, coll. Malfini, 2009, p. 132.

57. Ce faisant, le «Wann» se transforme, par paranomase, en «Wahn», la folie (voir v. 21), ce qui participe de l'appropriation critique du poème verlainien.

58. Voir Hermann H. Wetzel, op. cit.

59. Paul Celan, Tübinger Ausgabe, op. cit., p. 116-118/Bonner Ausgabe, op. cit., p. 249-250. 
traduite (v. 56-61)60, transposée, pour être actualisée («kontemporan», v. 46), en passant du personnage historique des années 1800 à l'Allemagne du XXe siècle61. Dans la perspective du poème de Celan, le propos d'Apollinaire posséderait ainsi une dimension quasi prophétique par rapport à la Shoah.

L'ensemble de ces cinq hypotextes en langue étrangère constitue une sorte de matrice initiant le processus d'écriture, ce qui semble particulièrement vrai pour les citations de Verlaine et d'Apollinaire qui, à la manière d'épigraphes, sont mises en exergue dans le premier brouillon pour ensuite être intégrées à la création du texte ${ }^{62}$. Cependant, il ne s'agit pas de citations au sens propre, mais ces mots sont masqués au cours de la genèse du poème, selon un procédé généralisé chez Celan 63 . En outre, ces citations, ces séquences intertextuelles, fonctionnent comme des souches hétérolingues à partir desquelles se tisse un réseau de significations et se déploie l'écriture du poème. Ces séquences en langue étrangère se voient en effet intégrées dans le processus créatif jusqu'à transcender les frontières entre les langues pour créer des mots hybrides.

\section{Le fil conducteur de la genèse du poème}

Après l'étude du plurilinguisme de la version publiée du poème et celle du premier brouillon, il convient à présent d'approfondir l'analyse du principal fil conducteur de la genèse du texte. Celui-ci conduit des citations en langues étrangères se trouvant à l'origine de l'écriture du poème jusqu'à son titre qui, comme évoqué plus haut, peut se lire comme un condensé des procédés formels et des thèmes et motifs utilisés par le texte. De manière simplifiée, l'évolution lexicale qui aboutit à «Huhediblu» mène du verbe «fleurir» chez Verlaine, traduit en allemand («blühen»), vers l'idée de tuer, que le poème associe à l'interjection onomatopéique «hue!» (« hüh!» en allemand64).

Cette association servira de pivot, d'axe central, pour l'écriture du poème, grâce à l'emploi de procédés phonétiques et morphologiques complexes. La mise en place de la correspondance fleurir-tuer, étape cruciale dans la genèse du texte, s'opère dès le deuxième manuscrit $(\mathrm{H} 5)$, où les vers «On tue les poètes / Pour les citer après » sont complétés par «Hü65 - on tue, [les poètes...]», les mots «on tue» ayant été soulignés par l'auteur66. Ce télescopage entre l'interjection martiale destinée à faire avancer un cheval et l'idée de tuer une personne se retrouve dans la version publiée où elle rejoint, de manière quasi circulaire, les vers (traduits) de Verlaine («Oh, quand...») : «Hüh - on tue... Ja, wann ?» (v. 19).

En ce sens, le titre «Huhediblu» ou «Hüh/edi/blü[h]» (je reviendrai sur l'oscillation $u / u i)$ pourrait donc d'abord se lire comme la transformation des roses de Verlaine, à l'origine du poème, en une expression synthétique qui, derrière un apparent non-sens pseudo-dadaïste, associe la floraison à l'idée de la profération d'une parole menaçante, voire assassine, incarnée par le «mot coupe-tête 67 » du vers 48 . La métaphore de la croissance, très présente dans tout le recueil, se charge ici de négativité, à l'image même du titre La Rose de personne. Cette association entre les roses et la mort est renforcée par l'existence du binôme «hüh»+ « hott», l'interjection allemande se complétant implicitement par ce deuxième élément ${ }^{68}$. Convoqué également par le titre du poème («Hu[hott]hedibluh»), «hott» est un élément hybride pouvant se dédoubler en «hot», mot anglais (voir la citation d'Enzensberger, v. 61), et «hotte», sa paronomase française potentielle, renvoyant à la Shoah (voir ci-dessus).

60. La partie finale du poème cite les noms des principaux protagonistes du poème d'Apollinaire, en renvoyant à leurs forfaits meurtriers.

61. De Schinderhannes le poème dit qu'il «se met au travail» (v. 57) à l'époque présente («kontemporan», v. 56).

62. Comme le montre très bien le premier brouillon du poème (voir fig. 1), les citations de Verlaine et d'Apollinaire sont séparées du premier vers du poème par un trait. La deuxième citation semble de surcrô̂t décalée vers le centre de la ligne.

63. Jürgen Lehmann, op. cit., p. 8.

64. En sortant de la logique proprement génétique, le néologisme «Huhediblu» peut susciter bien d'autres associations encore : «dis» pour le dire poétique; «blu» pour bleu en italien (une couleur essentielle dans la poésie de Celan); «Blut » pour le sang en allemand (je remercie Emilio Sciarrino pour ses suggestions à cet égard).

65. Cette graphie erronée ne sera corrigée que dans la deuxième dactylographie (H3) du poème. Voir Paul Celan, Tübinger Ausgabe, op. cit., p. 117.

66. Paul Celan, Tübinger Ausgabe, op. cit., p. 116/Bonner Ausgabe, op. cit., p. 251.

67. Le mot de septembre du vers verlainien est soumis à un traitement semblable qui, au cours de la genèse du poème, «se transforme en chiffre de la nostalgie nazie», comme le dit Hermann H. Wetzel, op. cit., p. 143. 68. Comme le note Barbara Wiedemann (Paul Celan, Die Gedichte, Kommentierte Gesamtausgabe, op. cit., p. 705-706), cette interjection apparaît fréquemment sous la plume de Celan à cette époque. 


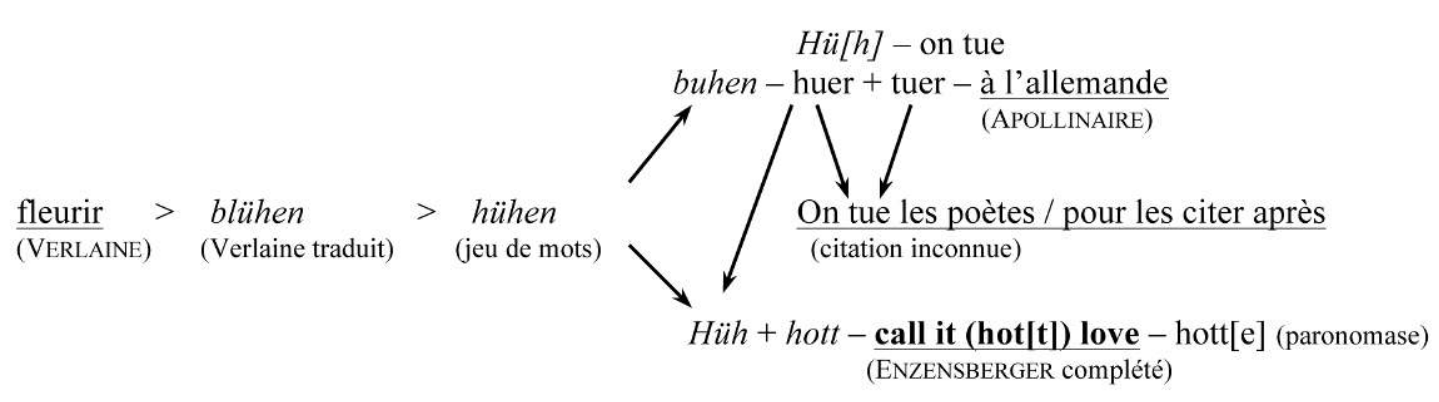

Fig. 3 : schéma lexical simplifié d'un fil conducteur génétique du poème à partir de ses intertextes hétérolingues

Analysé de cette manière, le fil génétique du poème pourrait donner lieu à la présentation schématique proposée dans la figure 3. Les quatre citations ou séquences hétérolingues qui servent de matrice au texte (Verlaine; Apollinaire ; Enzensberger; citation inconnue) ont été soulignées et se trouvent aux extrémités du schéma dont le centre implicite serait le titre du poème «Huhediblu». La différence linguistique a été mise en évidence en différenciant entre le romain pour le français, l'italique pour l'allemand, le gras pour l'anglais et souligné pour le français.

\section{Les procédés morphologiques et phonétiques}

En retraçant la genèse du poème, je me suis efforcé jusqu'ici de privilégier le plan sémantique, afin de restituer aussi clairement que possible la logique (le sens) des choix d'écriture de Celan. Or, force est de constater, à commencer par le titre, que le texte travaille autant sur la forme que sur le fond. À ce titre, le poème est tout à fait représentatif du recueil La Rose de personne dont l'un des principes esthétiques fondamentaux consiste à mettre en mouvement les signes et leurs relations convenues à travers les jeux avec le lien sons-sens ${ }^{69}$, en travaillant au niveau morphologique et phonétique des différentes langues en jeu.

Dès les premiers états génétiques, Celan soumet les mots du poème à des procédés formels complexes impliquant des inversions et permutations de syllabes, à la manière d'anagrammes, des jeux phoniques, des onomatopées, etc. Les brouillons, tout comme le poème publié, comportent de nombreux jeux associatifs avec des sons et des lettres, qui excèdent la logique lexico-sémantique. Pour mettre en évidence cette dimension quasi lettriste de la fabrique du texte, l'imbrication du son et du sens des différentes langues en jeu, examinons brièvement la genèse des vers 14-21, qui constituent la cellule génétique dont va émerger directement le titre du poème.
Dès le premier manuscrit (H6), on peut observer un jeu formel à partir de la traduction en allemand de l'intertexte verlainien («Oh, quand refleuriront...»), jeu qui consiste à agglutiner les différents mots du vers : «- wann blühen, wann, / wannblühen die, wannblühen wiederdie

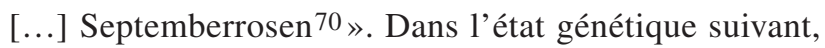
cette contraction va intégrer un élément supplémentaire, l'expression «Hüh [hott]» déjà analysée : «Wann, / wann blühen, wann, / wannblühendie, hühendi[eb] [blüh71 » pour aboutir, deux lignes plus bas, à l'association cruciale : «Hü - on tue». On remarque qu'à la contraction des mots s'est ici ajoutée une logique permutative, anagrammatique, proche de la métathèse, faisant s'entremêler «Hüh[en]» et «blüh[en]»: «hühendi[eb]] blüh». Ce qui est intéressant dans notre contexte, c'est que cette opération peut se lire comme la création d'un nouveau verbe allemand «hühen» évoquant fortement le verbe français «huer», qui s'intègre parfaitement dans le réseau signifiant du poème, dans le sens où ce verbe renvoie à la diffamation dont Celan faisait alors l'objet.

Lors du passage à la première dactylographie du poème $(\mathrm{H} 4)$, les vers 14-21 vont acquérir leur forme quasi définitive ${ }^{72}$; puis, dans l'état génétique suivant, qui correspond à la deuxième dactylographie (H3), l'un des éléments de ce passage se transformera en titre du poème :

69. Voir Jürgen Lehmann, op. cit., p. 21 et passim.

70. Paul Celan, Bonner Ausgabe, op. cit., p. 249. Pour ce passage, je me limite à citer cette seule édition, car sa transcription me semble plus claire. 71. Ibid., p. 251. Le signe $\int$ utilisé par l'édition de Bonn indique en l'occurrence le fait que l'auteur a opéré une contraction entre deux éléments initialement séparés. Les crochets signalent une suppression. Le soulignement en pointillé indique une lecture conjecturale, notamment par rapport à la différence lettre minuscule/majuscule.

72. Ibid., p. 254. Il faut néanmoins préciser que certaines contractions opérées durant la genèse du poème sont annulées par la version définitive (voir notamment v. 16); ce procédé, mélangeant plusieurs langues, semble constitutif de la fabrique du poème, sans toujours se maintenir dans la version publiée. 
«Huhediblu73». En l'occurrence, l'analyse génétique permet donc de motiver et de clarifier (autant que faire se peut) ce titre à l'allure si étrange, pouvant sembler incompréhensible. Au passage, ce néologisme hybride aura perdu, par syncope et élision, la consonne « $\mathrm{n}$ » du milieu, issue de l'infinitif ou du pluriel allemand, ainsi que son «h» final (hühendiblüh).

La transformation la plus importante consiste cependant en la suppression, dès l'étape précédente $(\mathrm{H} 4)^{74}$, des trémas, ce qui altère profondément la prononciation allemande de ce mot, qui passe de [hy:ədi:bly:] à [hu:ədi:blu:]. Le paradoxe de ce jeu phonique bilingue veut qu'il faille désormais prononcer le titre du poème à la française ( $($ ' « $\mathrm{u}$ » étant prononcé [y] et non pas [u]) pour faire apparaître phonétiquement les éléments allemands ( «Hüh» et «blühen») qui le composent. En même temps, la suppression des trémas, cette refrancisation d'une expression traduite à l'origine du français, renforce fortement l'hypothèse que le titre comporte, outre les éléments allemands cités, le verbe français «huer $75_{»}$ : «Hue[r]diblu». En allemand, ce verbe français correspondrait d'ailleurs à «buhen», verbe qu'on pourrait également entendre résonner à travers les jeux phonético-sémantiques qu'on vient de décrire (voir fig. 3).

\section{D'une floraison à l'autre}

En fin de compte, le titre du poème, qui pourrait donc se lire comme la traduction contractée, transformée, commentée du vers verlainien noté en haut du premier brouillon, fait apparaître une superposition de la phonétique et de la sémantique françaises et allemandes. Il s'agit d'un titre hybride qui semble osciller entre les deux langues, un phénomène qui peut à juste titre être qualifié de translingue. $\mathrm{Vu}$ sous cet angle, le titre «Huhediblu» représente une sorte de synthèse des procédés qui accompagnent toute la genèse du poème, né d'un réseau de sens et de sons provenant de l'allemand et du français, sans oublier l'anglais. C'est un réseau translingue dont le pivot était constitué par l'expression «Hü - on tue» qui se retrouve à l'interstice des différents hypotextes et intertextes hétérolingues tirés de Verlaine, Apollinaire, Enzensberger, etc.

En apparence dépourvu de sens, ce titre condense ainsi la «distanciation vis-à-vis de la poétique verlainienne ${ }^{76}$ » qui se trouve au cœur et à l'origine du texte. Il véhicule l'introduction du thème de l'assassinat et de la mort dans l'image originelle de la floraison, tout en y faisant résonner l'idée de la diffamation («huer»/«buhen») dont le poète se sentait victime. La floraison, dont le poème parle, n'est plus celle des roses de Verlaine, mais celle de la parole assassine, le retour des fleurs renvoyant désormais au «Nimmermenschstag im September/jour de personne en septembre» (v. 13), expression qui semble faire référence aux catastrophes passées ou à venir77. C'est en langue française, en réécrivant le vers de Verlaine, que Celan clôt son poème, en chargeant la nostalgie verlainienne d'une forte ambiguïté, qui, de manière circulaire, renvoie au titre du poème : «Oh quand refleuriront, oh roses, vos septembres? (v. 63). À travers le mouvement du texte, les « roses de septembre», leur «floraison», se seront chargées de connotations hautement menaçantes, mortifères, en pointant probablement aussi vers le mal qui guettait le poète dès cette époque : la folie $\left(« \mathrm{Wahn}^{78} »\right)$.

Sous cet angle, le titre du poème est loin de faire référence à quelque «hurluberlu79»; derrière le non-sens apparent des jeux de mots enfantins apparaît en effet une dimension dramatique. Dans ce jeu sérieux se mêlent la dimension tragique de l'histoire, sous forme de renvois à l'antisémitisme et au génocide des juifs, la biographie d'un poète profondément affecté par la diffamation dont il faisait l'objet, obsédé par l'idée d'un retour des assassins, et une approche expérimentale du langage poétique renvoyant au dadaïsme, au lettrisme, à la poésie concrète. Pour ce faire, Celan se sert de procédés qui dépassent clairement le cadre monolingue de l'écriture, en ouvrant un espace de création entre les langues dont la dynamique alimente, voire conditionne la naissance du poème.

Par conséquent, bien qu'il soit plus discret dans la version publiée du texte que dans ses brouillons, le plurilinguisme

73. Ibid., p. 256.

74. Ibid., p. 251.

75. Ce rapprochement est également suggéré par la traduction que Martine Broda donne du titre : «Flhuerissentles», voir supra.

76. Hermann H. Wetzel, op. cit., p. 145.

77. Au sujet de la signification de cette date, voir le commentaire de Wiedemann (Paul Celan, Die Gedichte, op. cit., p. 705) et de Konietzny (op. cit., p. 300).

78. Voir la paranomase «Wann» - «Wahn» aux vers 20-21.

79. Rapprochement suggéré par Hermann H. Wetzel, op. cit., p. 146. 
constitue bel et bien une dimension fondamentale du poème «Huhediblu», comme le montre l'analyse de sa genèse. À cet égard, on peut parler de l'existence d'une véritable trame plurilingue qui a guidé la naissance de ce texte. À l'instar du titre du poème, la genèse du poème entre les langues, à partir d'une série d'intertextes hétérolingues qui en constituent pour ainsi dire la matrice, reste inscrite dans sa version définitive, publiée. Si on a souvent souligné le lien entre poésie et traduction chez Celan ${ }^{80}$, les brouillons de «Huhediblu» suggèrent en outre l'existence, chez ce poète, d'un lien intime entre poésie et plurilinguisme, entre plurilinguisme et créativité poétique.

Somme toute, l'analyse de la genèse de certains poèmes de Celan, et, plus généralement, l'examen du fonds posthume (manuscrits, carnets, correspondances, journaux intimes, etc.), nous enseigne que l'opposition entre monolinguisme et plurilinguisme n'y est plus totalement opératoire. À cet égard, on pourrait aller jusqu'à dire que la poésie de Celan est à la fois monolingue et plurilingue, dans la mesure où elle est l'émanation littéraire d'une contradiction existentielle qui habitait ce poète extraterritorial, survivant de la Shoah. La volonté - parfaitement compréhensible, légitime, juste - de Celan de s'inscrire dans la tradition poétique allemande ne doit pas masquer la dimension profondément translingue de son œuvre, dont la qualité esthétique repose notamment sur une certaine babélisation de la langue allemande.

80. Voir notamment Ute Harbusch, Gegenübersetzungen, Paul Celans Übertragungen französischer Symbolisten, Göttingen, Wallstein, 2005. 
Auteur d'une thèse sur la réception française de Paul Celan, DiRK WEISSMANN est professeur des universités à l'université Toulouse - Jean Jaurès. Il est membre du Centre de recherches et d'études germaniques (CREG, EA 4151) et chercheur associé à l'ITEM (équipe «Multilinguisme, traduction, création»). Ses travaux portent sur la littérature d'expression allemande, en particulier sur sa dimension plurilingue et interculturelle, ainsi que sur la théorie et la pratique de la traduction littéraire.

dirk.weissmann@univ-tlse2.fr

Cet article se propose d'aborder le problème du multilinguisme dans l'œuvre du poète germanophone Paul Celan (1920-1970), en examinant la genèse de son poème «Huhediblu», publié en 1963 dans le recueil Die Niemandsrose (La Rose de personne). Si la version publiée du poème comporte un certain nombre d'éléments hétérolingues, l'examen des brouillons permet de montrer que le multilinguisme a joué un rôle éminemment créateur dans l'écriture de ce texte. Celui-ci est en effet d'abord né en marge d' extraits de poèmes en langue étrangère, et sa genèse repose sur de complexes processus translingues. Le titre même du poème, néologisme condensant la forme et le fond du texte, est le résultat d'une rencontre, d'une confrontation, d'une hybridation entre les langues. On peut ainsi parler de l'existence d'une véritable trame multilingue qui a présidé à la naissance de ce poème, trame qu'on suivra à travers les différentes étapes de sa genèse.

This article approaches the problem of multilingualism in the works of the German poet Paul Celan (1920-1970), by examining the genesis of his poem "Huhediblu" published in 1963 in Die Niemandsrose (Nobody's Rose). If the published version of the poem contains several heterolingual elements, the study of drafts reveals that multilingualism played a major creative role in the writing of this text. Indeed, this poem was first born in parallel with extracts of poems in a foreign language, and its genesis is based on complex translingual processes. The very title of the poem, a neologism condensing form and content, is the result of a meeting or confrontation, hybridization between languages. We can thus speak of the existence of an actual multilingual framework that presided over the birth of this poem, one that we will follow throughout the various stages of its genesis.

Dieser Beitrag beschäftigt sich mit dem Problem der Mehrsprachigkeit im Werk des deutschsprachigen Lyrikers Paul Celan (1920-1970). Auf der Grundlage textgenetischer Beobachtungen soll die Rolle der Mehrsprachigkeit im Entstehungsprozess seines Gedichts „Huhediblu“ aus dem 1963 veröffentlichen Gedichtzyklus Die Niemandsrose analysiert werden. Lässt die publizierte Fassung dieses Textes bereits eine ganze Reihe heterolingualer Elemente erkennen, so kann durch eine Betrachtung der Vorstufen gezeigt werden, dass Mehrsprachigkeit eine tragende Rolle beim Entstehungsprozess des Gedichts gespielt hat. So scheint sich die thematische und formale Konzeption des Gedichts aus einer spielerisch-kritischen Aneignung fremdsprachiger Gedichtzitate heraus entwickelt zu haben. Der wortschöpferische Titel des Gedichts verdichtet diesen Entstehungsprozess zwischen den Sprachen, insofern er aus einem translingualen Verfahren resultiert, in dem sich die verschiedenen Sprachen überlagern und durchkreuzen. Insgesamt besitzt Celans

\section{Monolinguisme - plurilinguisme - translinguisme}

Gedicht eine Art mehrsprachiger Matrix, die anhand der verschiedenen Etappen der Textgenese nachgezeichnet werden soll.

Este artículo se propone abordar el problema del multilingüismo en la obra del poeta germanófono Paul Celan (1920-1970), estudiando la génesis de su poema "Huhediblu", publicado en 1963 en el libro Die Niemandsrose (La Rose de personne). Si la versión publicada del poema comporta algunos elementos heterolingües, el examen de los borradores pone en evidencia que el multilingüismo ha jugado un papel eminentemente creador en la escritura de ese texto. En efecto, éste nace ante todo en los márgenes de fragmentos de poemas en lengua extranjera y su génesis se basa en complejos procesos translingües. El título mismo del poema -neologismo que condensa la forma y el fondo del texto- es el resultado de un encuentro, una confrontación, una hibridación entre las lenguas. De este modo se puede hablar de la existencia de una verdadera trama multilingüe que ha signado el nacimiento de este poema, trama que observaremos a través de las diferentes etapas de su génesis.

Este artigo aborda o problema do multilinguismo na obra do poeta germanófono Paul Celan (1920-1970), examinando a gênese do poema "Huhediblu", presente na coletânea Die Niemandsrose (A Rosa de Ninguém), de 1963. Se a versão publicada contém um certo número de elementos heterolíngues, a análise dos rascunhos revela que o multilinguismo teve um papel eminentemente fecundo no processo de escrita do texto. Na realidade, este nasceu à margem de trechos de poemas escrito em língua estrangeira e sua gênese apoia-se em complexos processos translíngues. O próprio título do poema, neologismo que condensa a forma e o conteúdo do texto, resulta de um encontro, de um confronto, de uma hibridação entre línguas. Pode-se, portanto, afirmar a existência de uma verdadeira trama multilíngue a presidir o surgimento do poema, trama que será possível acompanhar através das diferentes etapas de sua gênese.

L'articolo propone un approccio al problema del multilinguismo nell'opera del poeta germanofono Paul Celan (1920-1970) attraverso l'esame della genesi del suo poema Huhediblu, pubblicato nel 1963 nella raccolta Die Niemandsrose (La Rosa di nessuno). Se la versione edita del poema comporta un certo numero di elementi eterolinguistici, l'esame dei manoscritti preparatori permette di dimostrare che il multilinguismo ha avuto un'importante funzione creativa nella redazione di questo testo. Nato dapprima a margine di brani di poemi in lingua straniera, la sua genesi riposa su complessi processi translinguistici. Il titolo stesso del poema, neologismo che condensa forma e contenuto del testo, è il risultato di un incontro, di un confronto, di un'ibridazione tra le lingue. Possiamo così parlare dell'esistenza di una vera e propria trama multilingue che presiede alla nascita di questo poema, trama che seguiremo lungo le diverse fasi della sua genesi. 